University of Nebraska - Lincoln

DigitalCommons@University of Nebraska - Lincoln

Faculty Papers and Publications in Animal

Science

Animal Science Department

January 1998

\title{
Effect of Ignoring Random Sire and Dam Effects on Estimates and Standard Errors of Breed Comparisons
}

\author{
K. L. Barkhouse \\ University of Nebraska-Lincoln \\ L. Dale Van Vleck \\ University of Nebraska-Lincoln, dvan-vleck1@unl.edu \\ Larry V. Cundiff \\ University of Nebraska-Lincoln, Icundiff2@unl.edu
}

Follow this and additional works at: https://digitalcommons.unl.edu/animalscifacpub

Part of the Animal Sciences Commons

Barkhouse, K. L.; Van Vleck, L. Dale; and Cundiff, Larry V., "Effect of Ignoring Random Sire and Dam Effects on Estimates and Standard Errors of Breed Comparisons" (1998). Faculty Papers and Publications in Animal Science. 272.

https://digitalcommons.unl.edu/animalscifacpub/272

This Article is brought to you for free and open access by the Animal Science Department at DigitalCommons@University of Nebraska - Lincoln. It has been accepted for inclusion in Faculty Papers and Publications in Animal Science by an authorized administrator of DigitalCommons@University of Nebraska - Lincoln. 


\title{
Effect of Ignoring Random Sire and Dam Effects on Estimates and Standard Errors of Breed Comparisons ${ }^{1}$
}

\author{
K. L. Barkhouse*, L. D. Van Vleck ${ }^{\dagger, 2}$, and L. V. Cundiff \\ *Department of Animal Science, University of Nebraska, Lincoln, 68583-0908 and \\ Roman L. Hruska U.S. Meat Animal Research Center, \\ ARS, USDA, †Lincoln and ₹Clay Center, NE 68933
}

\begin{abstract}
Data were weights of $F_{1}$ calves and weaning weights of top-cross progeny from sires and maternal grandsires of 13 breeds. Three analyses were performed on each trait to obtain estimates and standard errors of breed effects needed to calculate across-breed EPD and accuracies. Model (R) for records of $F_{1}$ progeny contained fixed effects for birth year and date of birth, sex, age and breed of dam, and breed of sire, and a random residual effect. The second analysis included random effects for sires (RS), and the third analysis included random effects for sires and dams (RSD). In maternal analysis of top-cross progeny, model $\left(R_{m}\right)$ contained fixed effects for cycle of experiment, age of dam, year of birth, sex, breeds of maternal grandam and grandsire, and breed of sire,
\end{abstract}

and a random residual effect. In addition, the second and third analyses fit random effects for maternal grandsires $\left(R S_{m}\right)$ and for maternal grandsires and daughters of maternal grandsires $\left(R S D_{m}\right)$. Estimates of breed of sire effects changed only slightly for different models. Total variance increased in RSD and RS relative to $R$. Standard errors of breed of sire comparisons were underestimated with Model R, compared to Models RS and RSD. Standard errors of other contrasts were generally not affected. Variance components, breed effects, and standard errors followed patterns for $R_{m}, R_{m}$, and $R_{S D}$ similar to those for R, RS, and RSD. I gnoring random variation due to sires and dams underestimated standard errors of breed of sire comparisons.

Key Words: Growth, Breeds, Beef Cattle, Breeding Value

@1998 American Society of Animal Science. All rights reserved.

J. Anim. Sci. 1998. 76:2279-2286

\section{Introduction}

Procedures to calculate adjustment factors to add to within-breed EPD to allow comparisons across breeds rely on estimates of differences among breeds of sire. One limitation of across-breed EPD is the precision with which these differences are estimated.

Previous analyses of data from the Germ Plasm Evaluation (GPE) program conducted at the U. S. Meat Animal Research Center (MARC) in Clay Center, Nebraska, estimated breed of sire differences and then adjusted these differences for sire sampling and genetic trend (Notter and Cundiff, 1991; Cundiff, 1993; Núñez-Dominguez et al., 1993). The adjusted

${ }^{1}$ Published as paper no. 11592, J ournal Ser., Nebraska Agric. Res. Div., Univ. of Nebraska, Lincoln 68583-0908.

${ }^{2}$ To whom correspondence should be addressed.

Received J uly 10, 1996.

Accepted August 27, 1997. breed of sire differences are used with within-breed EPD to predict across-breed EPD. These analyses accounted for various fixed effects but did not include terms to account for variance due to effects of sires and dams.

I gnoring random effects will result in underestimation of standard errors for breed of sire contrasts (Komender and Hoeschele, 1989; Gill, 1991). The objective of this paper, therefore, was to determine the effect of ignoring variation due to sires and dams on estimates and standard errors of differences among breeds of sire.

\section{Materials and Methods}

Data on birth weight (BWT), weaning weight at $205 \mathrm{~d}$ (WWT), and $365 \mathrm{~d}$ weight (YWT) were available from Cycles I through $V$ of the GPE program conducted at MARC. Data were obtained for two analyses: records of first-cross progeny of 13 breeds of sires and records of three-breed-cross grand-progeny of maternal grandsires from the 13 breeds. 
Table 1. Number of MARC sires and number of $F_{1}$ progeny weaned by breed of sire and cycle of GPE

\begin{tabular}{lcrrrrr}
\hline \hline & & \multicolumn{5}{c}{ Number of progeny } \\
\cline { 3 - 7 } Breed & No. of sires & Cycle I & Cycle II & Cycle III & Cycle IV & Cycle V \\
\hline P. Hereford & 30 & 36 & 29 & 79 & 68 & 202 \\
Hereford & 36 & 74 & 53 & 91 & 96 & 86 \\
Angus & 56 & 51 & 32 & 44 & 83 & 254 \\
Shorthorn & 25 & 0 & 0 & 0 & 170 & 0 \\
Brahman & 26 & 0 & 0 & 119 & 0 & 215 \\
Simmental & 27 & 366 & 0 & 0 & 0 & 0 \\
Limousin & 20 & 338 & 0 & 0 & 0 & 0 \\
Charolais & 60 & 308 & 0 & 0 & 175 & 0 \\
Maine-Anjou & 15 & 0 & 155 & 0 & 0 & 0 \\
Gelbvieh & 24 & 0 & 193 & 0 & 143 & 0 \\
Pinzgauer & 16 & 0 & 0 & 353 & 62 & 0 \\
Tarentaise & 7 & 0 & 0 & 191 & 0 & 0 \\
Salers & 26 & 0 & 0 & 0 & 175 & 0 \\
Total & 368 & 1,173 & 462 & 877 & 972 & 757 \\
\hline
\end{tabular}

aCalves were born from 1970 to 1972 in Cycle I, 1973 to 1974 in Cycle II, 1975 to 1976 in Cycle III, 1986 to 1990 in Cycle IV, and 1992 to 1994 in Cycle V.

\section{First-Cross Progeny}

First-cross calves resulted from mating 13 breeds of sire to Hereford, Angus, or MARC III composite (1/4 Angus, 1/4 Hereford, 1/4 Pinzgauer, 1/4 Red Poll) cows. Angus, Hereford, and Polled Hereford sires were used across all cycles. Totals of 15 Hereford, 15 Polled Hereford, 36 Angus, and 13 Brahman bulls produced progeny in two or more cycles. Records of purebred calves were deleted from the data set, as were those of calves resulting from matings between Polled Hereford and Horned Hereford, due to a presumed lack of heterosis. The remaining progeny were from crosses with MARC III Composite cows and would exhibit at least $75 \%$ of individual heterosis. Further edits to the data removed records of animals raised by a foster dam or those with abnormal birth or rearing codes. For BWT, measurements on bull and heifer calves were used in the analyses, and for WWT and YWT, measurements on steers and heifers were used. Only records of those with sires having reported EPD for BWT, WWT, or YWT were used. Edits resulted in 4,703 BWT records, 4,241 WWT records, and 3,917 YWT records. Table 1 shows the number of sires and number of $F_{1}$ progeny weaned by cycle and breed of sire.

Calves were born in late February through early May. All calves were weighed and dehorned, and male calves were castrated within $24 \mathrm{~h}$ after birth. Calves were creep-fed through weaning, which occurred at approximately $200 \mathrm{~d}$ of age so that direct effects of sire and sire breed would be fully expressed. After weaning, heifers were managed to produce their first calf by $2 \mathrm{yr}$ of age. Heifers and steers were fed ad libitum after weaning. Detailed descriptions of management procedures have been reported by Smith et al. (1976) and Gregory et al. (1978, 1979).
Three-Breed-Cross Progeny

Weaning weight $(205-d)$ records $(n=6,576)$ of progeny produced by $F_{1}$ cows ( $\mathbf{M W W T}$, as a trait of the calf) were available from the GPE program. Three-breed-cross progeny were produced by pasture (multisire) mating a portion of the $F_{1}$ females in the former data set to unidentified sires of an unrelated breed. In Cycle I, $F_{1}$ heifers were pasture-mated to Hereford, Angus, Brahman, Devon, and Holstein sires, to Hereford, Angus, Maine-Anjou, Chianina, or Gelbvieh sires for their second potential calvings, and to Brown Swiss sires for subsequent calvings. Cycle II heifers were pasture-mated to Hereford, Angus, Brangus, or Santa Gertrudis sires and to Simmental-cross bulls for subsequent calvings. Cycle III and IV heifers were pasture-mated to Red Poll bulls and to Simmental bulls for subsequent calvings. Records of progeny from matings exhibiting less than $100 \%$ of individual and maternal heterosis were deleted. Records of progeny of Polled Hereford $\times$ Hereford cows were deleted because heterosis of Polled Hereford $x$ Hereford crosses was assumed to be zero. Other edits were similar to those for records of first-cross progeny. Table 2 shows the number of maternal grandsires and number of three-breed-cross progeny weaned by year of birth and breed of maternal grandsire. Preweaning management was similar to that described for the first-cross progeny except that they were not creep-fed (Notter et al., 1978).

\section{Statistical Analyses}

Records of $F_{1}$ progeny and three-breed-cross calves were analyzed using three models. In both cases, the models represented sequential changes in sources of variance. Models were compared by examination of components of variance, solutions (e.g., breed of sire 
Table 2. Number of maternal grandsires (MGS) and number of three-breed-cross progeny weaned by breed of MGS and year

\begin{tabular}{|c|c|c|c|c|c|c|c|c|c|c|c|c|c|c|c|c|c|c|c|}
\hline \multirow[b]{2}{*}{ Breed } & \multirow[b]{2}{*}{ MGS } & \multicolumn{18}{|c|}{ Year } \\
\hline & & 72 & 73 & 74 & 75 & 76 & 77 & 78 & 79 & 80 & 81 & 82 & 88 & 89 & 90 & 91 & 92 & 93 & 94 \\
\hline P. Hereford & 26 & - & 1 & 9 & 14 & 22 & 43 & 49 & 48 & 38 & 40 & 32 & 10 & 12 & 19 & 26 & 31 & 29 & 42 \\
\hline Hereford & 26 & 8 & 12 & 18 & 24 & 34 & 55 & 62 & 53 & 41 & 43 & 34 & 10 & 14 & 27 & 32 & 35 & 31 & 27 \\
\hline Angus & 38 & 1 & 11 & 8 & 19 & 21 & 29 & 26 & 30 & 16 & 19 & 14 & 19 & 27 & 27 & 38 & 43 & 39 & 37 \\
\hline Shorthorn & 22 & - & - & - & - & - & - & - & - & - & - & - & 12 & 23 & 28 & 39 & 59 & 58 & 36 \\
\hline Brahman & 19 & - & - & - & - & - & 24 & 27 & 34 & 34 & 35 & 32 & - & - & - & - & - & - & 32 \\
\hline Simmental & 27 & 34 & 77 & 122 & 122 & 128 & 116 & 117 & 80 & - & - & - & - & - & - & - & - & - & - \\
\hline Limousin & 20 & 35 & 56 & 123 & 116 & 121 & 122 & 115 & 76 & - & - & - & - & - & - & - & - & - & - \\
\hline Charolais & 54 & 26 & 45 & 84 & 88 & 84 & 82 & 81 & 44 & - & - & - & 16 & 26 & 42 & 57 & 65 & 70 & 44 \\
\hline Maine-Anjou & 14 & - & - & - & 16 & 51 & 54 & 58 & 54 & 47 & 48 & 29 & - & - & - & - & - & - & - \\
\hline Gelbvieh & 24 & - & - & - & 32 & 68 & 68 & 67 & 59 & 57 & 57 & 31 & 6 & 14 & 29 & 40 & 50 & 42 & 24 \\
\hline Pinzgauer & 15 & - & - & - & - & - & 58 & 87 & 86 & 79 & 80 & 67 & - & - & 3 & 15 & 22 & 25 & 23 \\
\hline Tarentaise & 6 & - & - & - & - & - & 29 & 60 & 63 & 63 & 65 & 61 & - & - & - & - & - & - & - \\
\hline Salers & 24 & - & - & - & - & - & - & - & - & - & - & - & 18 & 32 & 39 & 61 & 78 & 75 & 51 \\
\hline Total & 315 & 104 & 202 & 364 & 431 & 529 & 680 & 749 & 626 & 375 & 387 & 300 & 91 & 148 & 214 & 308 & 383 & 365 & 316 \\
\hline
\end{tabular}

contrasts), and apparent standard errors of contrasts. The word "apparent" indicates standard errors calculated from a model that might not be complete.

\section{First-Cross Progeny}

The first model $(\mathbf{R})$ included fixed class effects for year of birth ( BYR), sex of calf ( SEX), age of dam (AOD), breed of dam (BOD), and breed of sire (BOS), as well as a fixed covariate for J ulian birth date (J BD). Residual effects represented the only random effects in this model. The second model (RS) was the same as $R$ but included random effects due to sires nested within breed of sire. The final model (RSD) added a third random effect for dams nested within breed of dam.

All models were analyzed using a derivative-free algorithm to obtain REML estimates (Boldman et al., 1993). Solutions for fixed effects were obtained from the mixed-model equations, and contrasts and apparent standard errors were obtained from the appropriate portions of the inverse of the coefficient matrix.

\section{Three-Breed-Cross Progeny}

The purpose of these analyses was to estimate effects of the breeds of the maternal grandsires. All models included fixed effects for cycle of GPE (C), $A O D, C \times A O D$, BYR nested within $C \times A O D, S E X$, breed of maternal grandam (MGD), breed of maternal grandsire (MGS), and BOS nested within $\mathrm{C} \times$ AOD. The experimental units were three-way-cross progeny out of $F_{1}$ females. Year of birth of the threeway-cross progeny was partially cross-classified with cycle. Thus, year of birth included all effects of cycle in the $\mathrm{F}_{1}$ data set, but it was necessary to nest year in cycle to account for cycle and year effects combined for the three-way crosses. The first model $\left(R_{m}\right)$ included residual effects as the only source of variation. The second model $\left(R S_{m}\right)$ included an additional random effect for maternal grandsires nested within breed of MGS, and the third model $\left(R S D_{m}\right)$ also included a third source of variation due to dams (daughters of maternal grandsires) nested within maternal grandsire. Models were analyzed as described for the $F_{1}$ data.

\section{Results and Discussion}

True comparisons of models are impossible because true variances and solutions are not known. However, RSD will be considered the most complete and, therefore, the most correct model for these comparisons.

\section{Components of Variance}

Table 3 shows components of variance obtained from the three models for BWT, WWT, YWT, and MWWT. For all traits, changes in total phenotypic variance across models were trivial, indicating that components of variance in $R\left(R_{m}\right)$ and $R S\left(R S_{m}\right)$ represented a redistribution of total variance, primarily affecting residual variances. For the most complete models, sire variance accounted for between 5 and $12 \%$ of total variance in all traits. When dams were ignored, sire variance increased slightly for BWT, WWT, and YWT, and nearly doubled for MWWT, indicating confounding between direct and maternal effects of maternal grandsires. The increase in sire variance from RSD to RS for BWT, WWT, and YWT seems to be a result of variation due to dams being distributed more heavily to sire variance than to residual variance, indicating that confounding be tween effects of sires and unrelated dams was present, though negligible, as indicated by the magnitude of 
Table 3. Components of variance $\left(\mathrm{kg}^{2}\right)$ for sire $\left(\sigma_{\mathrm{s}}^{2}\right)$ and dam $\left(\sigma_{\mathrm{d}}^{2}\right)$ for birth weight (BWT), weaning weight (WWT), and yearling weight (YWT) and for maternal grandsire $\left(\sigma_{\mathrm{mgs}}^{2}\right)$, and daughter within maternal grandsire $\left(\sigma_{\mathrm{d} \mid \mathrm{m}}^{2}\right)$, for maternal weaning weight (MWWT), and for total variance $\left(\sigma_{\mathrm{T}}^{2}\right)$ for models ignoring random effects $\left(R\right.$ and $\left.R_{m}\right)$, including random sire or maternal grandsire effects (RS and $\mathrm{RS}_{\mathrm{m}}$ ) and including random dam or daughter within maternal grandsire effects (RSD and $\mathrm{RSD}_{\mathrm{m}}$ )

\begin{tabular}{cccc}
\hline \hline Trait & $\mathrm{R}\left(\mathrm{R}_{\mathrm{m}}\right)$ & $\mathrm{RS}\left(\mathrm{RS}_{\mathrm{m}}\right)$ & $\mathrm{RSD}\left(\mathrm{RSD}_{\mathrm{m}}\right)$ \\
\hline $\mathbf{B W T}$ & & & \\
$\sigma_{\mathrm{s}}^{2}$ & - & 2.5 & 2.3 \\
$\sigma_{\mathrm{d}}^{2}$ & - & - & 6.6 \\
$\sigma_{\mathrm{e}}^{2}$ & 22.6 & 20.4 & 14.0 \\
$\sigma_{\mathrm{T}}^{2}$ & 22.6 & 22.9 & 22.9 \\
$\mathbf{W W T}$ & & & \\
$\sigma_{\mathrm{s}}^{2}$ & - & 34 & 31 \\
$\sigma_{\mathrm{d}}^{2}$ & - & - & 233 \\
$\sigma_{\mathrm{e}}^{2}$ & 580 & 549 & 322 \\
$\sigma_{\mathrm{T}}^{2}$ & 580 & 583 & 586 \\
$\mathbf{Y W T}$ & & & \\
$\sigma_{\mathrm{s}}^{2}$ & - & 167 & 156 \\
$\sigma_{\mathrm{d}}^{2}$ & - & - & 329 \\
$\sigma_{\mathrm{e}}^{2}$ & 1,353 & 1,199 & 878 \\
$\sigma_{\mathrm{T}}^{2}$ & 1,353 & 1,366 & 1,363 \\
$\mathbf{M W W T}$ & & & \\
$\sigma_{\mathrm{mgs}}^{2}$ & - & 81 & 38 \\
$\sigma_{\mathrm{d} \mid \mathrm{m}}^{2}$ & - & - & 171 \\
$\sigma_{\mathrm{e}}^{2}$ & 448 & 392 & 256 \\
$\sigma_{\mathrm{T}}^{2}$ & 448 & 473 & 465 \\
\hline
\end{tabular}

the differences. When effects of sires and dams were ignored, residual variance was overestimated by as much as $80 \%$ relative to the complete models.

\section{Mixed-Model Solutions}

Breed of sire solutions for BWT, WWT, YWT, and MWWT are given in Tables 4, 5, 6, and 7, respectively. Breed of sire differences are expected to estimate half of the direct additive genetic differences among sire breeds assuming heterosis effects are equal for all crosses. The assumption of equal heterosis is reasonably valid for comparisons among Bos taurus breeds (i.e., all sire breeds except Brahman) but may not be valid for comparison between Bos taurus and Bos indicus breeds from crosses with Bos taurus dams. Estimates of heterosis in Bos indicus $\times$ Bos taurus crosses are generally about twice as great as those found in Bos taurus $\times$ Bos taurus crosses (e.g., Long, 1980). Thus, sire breed effects are expected to overestimate additive direct breed effects of the Brahman relative to those for all other breeds. All other breeds are expected to have benefited about the same amount from Bos taurus $\times$ Bos taurus heterosis effects. Inferences from this experiment involving $F_{1}$ crosses out of Hereford and Angus dams, the two most prominent breeds used in U.S. beef cow herds, judging from registration numbers, can be drawn to the commercial industry using Hereford and Angus in crossing systems for commercial production.

With all models, Brahman and Maine-Anjou sires had the heaviest progeny at birth, and Angus had the lightest. Rankings were similar for RS and R, with less than half of the 13 breeds changing rank as compared to rankings with RSD, and none by more than two places. Brahman, Gelbvieh, and Charolais sires produced the heaviest calves at weaning, and

Table 4. Solutions (Sol) for birth weight and rankings for breed of sire (kg, Angus as constraint) for models ignoring random effects (R), including random sire effects (RS), and including random sire and dam effects (RSD)

\begin{tabular}{|c|c|c|c|c|c|c|}
\hline \multirow[b]{2}{*}{ Breed of sire } & \multicolumn{2}{|c|}{$\mathrm{R}$} & \multicolumn{2}{|c|}{ RS } & \multicolumn{2}{|c|}{ RSD } \\
\hline & Sol. & Rank & Sol. & Rank & Sol. & Rank \\
\hline P. Hereford & 1.5 & 12 & 2.1 & 10 & 2.0 & 10 \\
\hline Hereford & 2.0 & 10 & 2.0 & 11 & 1.8 & 12 \\
\hline Angus & 0 & 13 & 0 & 13 & 0 & 13 \\
\hline Shorthorn & 3.8 & 5 & 3.5 & 5 & 3.3 & 5 \\
\hline Brahman & 6.0 & 1 & 6.3 & 1 & 6.3 & 1 \\
\hline Simmental & 4.0 & 4 & 4.0 & 4 & 3.8 & 4 \\
\hline Limousin & 2.0 & 10 & 1.9 & 12 & 2.0 & 11 \\
\hline Charolais & 4.3 & 3 & 4.2 & 3 & 4.3 & 3 \\
\hline Maine-Anjou & 5.5 & 2 & 5.4 & 2 & 5.0 & 2 \\
\hline Gelbvieh & 3.3 & 7 & 2.9 & 7 & 3.0 & 6 \\
\hline Pinzgauer & 3.6 & 6 & 3.0 & 6 & 2.5 & 8 \\
\hline Tarentaise & 2.5 & 9 & 2.4 & 9 & 2.2 & 9 \\
\hline Salers & 3.3 & 7 & 2.7 & 8 & 2.6 & 7 \\
\hline
\end{tabular}


Table 5. Solutions (Sol.) for weaning weight and rankings for breed of sire $(\mathrm{kg}$, Angus as constraint) for models ignoring random effects (R), including random sire effects (RS), and including random sire and dam effects (RSD)

\begin{tabular}{|c|c|c|c|c|c|c|}
\hline \multirow[b]{2}{*}{ Breed of sire } & \multicolumn{2}{|c|}{$\mathrm{R}$} & \multicolumn{2}{|c|}{ RS } & \multicolumn{2}{|c|}{ RSD } \\
\hline & Sol. & Rank & Sol. & Rank & Sol. & Rank \\
\hline P. Hereford & 2 & 11 & 4 & 11 & 3 & 11 \\
\hline Hereford & -4 & 13 & 0 & 12 & -1 & 13 \\
\hline Angus & 0 & 12 & 0 & 12 & 0 & 12 \\
\hline Shorthorn & 9 & 7 & 8 & 7 & 8 & 6 \\
\hline Brahman & 12 & 1 & 12 & 1 & 12 & 1 \\
\hline Simmental & 11 & 5 & 11 & 3 & 10 & 4 \\
\hline Limousin & 5 & 10 & 5 & 8 & 4 & 9 \\
\hline Charolais & 12 & 2 & 12 & 1 & 11 & 3 \\
\hline Maine-Anjou & 10 & 6 & 10 & 5 & 10 & 4 \\
\hline Gelbvieh & 12 & 2 & 11 & 3 & 12 & 1 \\
\hline Pinzgauer & 6 & 8 & 5 & 8 & 4 & 9 \\
\hline Tarentaise & 6 & 8 & 5 & 8 & 5 & 8 \\
\hline Salers & 11 & 4 & 10 & 5 & 8 & 6 \\
\hline
\end{tabular}

Angus calves remained among the lightest. Rankings remained relatively consistent when random effects were deleted from the models. None of the 13 breeds changed rank by more than two places.

For all models, Charolais sires were ranked as having progeny with the heaviest yearling weights, whereas Brahman sires were ranked as having the lightest. The considerable change in ranking of Brahman sires from first for BWT and WWT to last for YWT is a result of differences in postweaning gain being reflected in yearling weights, in addition to differences in WWT. Souza (1993) reported that progeny of Bos indicus sires, such as Brahman, had significantly lower postweaning gains than progeny of Bos taurus sires at MARC. Four breeds changed rank from RSD to RS, all by one place. Rankings changed more substantially for $\mathrm{R}$, with four breeds changing one place, three breeds changing two places, and one breed changing three places.

Rankings of maternal grandsire breeds were relatively consistent with all models. Brahman maternal grandsires produced the heaviest grandprogeny at weaning, and Polled Hereford maternal grandsires produced the lightest as estimated with all models.

In general, differences in breed of sire solutions remained similar in all models. Any changes seemed to occur in a relatively random manner. Rankings for all traits were generally consistent with those reported by Barkhouse et al. (1994). These results were from progeny raised under MARC conditions and may not be the same under all environmental conditions.

Solutions for BOD, SEX, and AOD are shown in Table 8 for BWT, WWT, and YWT.

Table 6. Solutions (Sol.) for yearling weight and rankings for breed of sire ( $\mathrm{kg}$, Angus as constraint) for models ignoring random effects (R), including random sire effects (RS), and including random sire and dam effects (RSD)

\begin{tabular}{|c|c|c|c|c|c|c|}
\hline \multirow[b]{2}{*}{ Breed of sire } & \multicolumn{2}{|c|}{$\mathrm{R}$} & \multicolumn{2}{|c|}{ RS } & \multicolumn{2}{|c|}{ RSD } \\
\hline & Sol. & Rank & Sol. & Rank & Sol. & Rank \\
\hline P. Hereford & -3 & 9 & -2 & 8 & -1 & 8 \\
\hline Hereford & -5 & 12 & -4 & 10 & -5 & 10 \\
\hline Angus & 0 & 8 & 0 & 7 & 0 & 7 \\
\hline Shorthorn & 15 & 3 & 12 & 3 & 12 & 3 \\
\hline Brahman & -11 & 13 & -12 & 13 & -12 & 13 \\
\hline Simmental & 15 & 3 & 12 & 3 & 11 & 4 \\
\hline Limousin & -3 & 9 & -4 & 10 & -6 & 11 \\
\hline Charolais & 18 & 1 & 16 & 1 & 16 & 1 \\
\hline Maine-Anjou & 15 & 3 & 13 & 2 & 13 & 2 \\
\hline Gelbvieh & 10 & 6 & 6 & 6 & 8 & 6 \\
\hline Pinzgauer & 1 & 7 & -2 & 8 & -3 & 9 \\
\hline Tarentaise & -4 & 11 & -5 & 12 & -6 & 11 \\
\hline Salers & 16 & 2 & 11 & 5 & 10 & 5 \\
\hline
\end{tabular}


Table 7. Solutions (Sol.) for maternal weaning weight and rankings for breed of maternal grandsire ( $\mathrm{kg}$, Angus as constraint) for models ignoring random effects

$\left(R_{m}\right)$, including random maternal grandsire effects $\left(R S_{m}\right)$, and including also random daughter within maternal grandsire effects $(\mathrm{RSD})_{\mathrm{m}}$

\begin{tabular}{|c|c|c|c|c|c|c|}
\hline \multirow[b]{2}{*}{ Breed of sire } & \multicolumn{2}{|c|}{$\mathrm{R}_{\mathrm{m}}$} & \multicolumn{2}{|c|}{$\mathrm{RS}_{\mathrm{m}}$} & \multicolumn{2}{|c|}{$\mathrm{RSD}_{\mathrm{m}}$} \\
\hline & Sol. & Rank & Sol. & Rank & Sol. & Rank \\
\hline P. Hereford & -8 & 13 & -5 & 13 & -6 & 13 \\
\hline Hereford & -1 & 12 & -1 & 12 & -1 & 12 \\
\hline Angus & 0 & 11 & 0 & 11 & 0 & 11 \\
\hline Shorthorn & 18 & 4 & 14 & 7 & 15 & 6 \\
\hline Brahman & 24 & 1 & 22 & 1 & 23 & 1 \\
\hline Simmental & 18 & 4 & 19 & 2 & 19 & 2 \\
\hline Limousin & 1 & 10 & 2 & 10 & 1 & 10 \\
\hline Charolais & 10 & 9 & 10 & 9 & 10 & 9 \\
\hline Maine-Anjou & 17 & 7 & 16 & 4 & 16 & 4 \\
\hline Gelbvieh & 21 & 2 & 18 & 3 & 19 & 2 \\
\hline Pinzgauer & 15 & 8 & 11 & 8 & 12 & 8 \\
\hline Tarentaise & 20 & 3 & 15 & 5 & 16 & 4 \\
\hline Salers & 18 & 4 & 15 & 5 & 15 & 6 \\
\hline
\end{tabular}

\section{Standard Errors of Contrasts}

Standard errors of BOS contrasts are given in Table 9 for BWT, WWT, YWT, and MWWT. Standard errors of contrasts of differences of BOS solutions from Angus solutions from models ignoring random effects were underestimated as compared to complete models for all traits. In fact, standard errors were underestimated by as much as $50 \%$ in $R\left(R_{m}\right)$ relative to RSD $\left(R S D_{m}\right)$. In general, results were consistent with those reported by Gill (1991). Apparent standard errors from RS were larger than those from RSD in all cases. This is a direct result of the larger sire components of variance for the RS model relative to the RSD model because the sire component of variance contributes heavily to the standard errors. For MWWT, standard errors with RSD were similar to those with RS but were slightly larger than with RS for four maternal grandsire breeds. The lack of consistency must be due to the data structure and repartitioning of components of variance for maternal grandsire and residual effects when effects of daughters within maternal grandsire are included. Underestimation of standard errors of breed differences resulting from the use of incorrect models may result in underestimation of prediction error variances associated with across-breed EPD obtained from breed comparisons (Van Vleck and Cundiff, 1994). Komender and Hoeschele (1989) reported similar patterns when models including or ignoring sires and dams were compared.

Ranges for standard errors of BOD, SEX, and AOD contrasts are given in Table 10. All traits showed similar patterns in standard errors across models.

Table 8. Estimates $(\mathrm{kg})$ for birth weight, weaning weight, and yearling weight of contrasts for fixed effects for models ignoring random effects (R), including random sire effects

(RS), and including random sire and dam effects (RSD)

\begin{tabular}{|c|c|c|c|c|c|c|c|c|c|}
\hline \multirow[b]{2}{*}{ Fixed effect } & \multicolumn{3}{|c|}{ Birth weight } & \multicolumn{3}{|c|}{ Weaning weight } & \multicolumn{3}{|c|}{ Yearling weight } \\
\hline & $\mathrm{R}$ & RS & RSD & $\mathrm{R}$ & RS & RSD & $\mathrm{R}$ & RS & RSD \\
\hline \multicolumn{10}{|c|}{ Breed of dam } \\
\hline Hereford & 0 & 0 & 0 & 0 & 0 & 0 & 0 & 0 & 0 \\
\hline Angus & -1.7 & -1.7 & -1.7 & 18 & 18 & 19 & 16 & 16 & 16 \\
\hline MARC III & .7 & 1.0 & 1.2 & 13 & 13 & 15 & 10 & 9 & 11 \\
\hline \multicolumn{10}{|l|}{ Sex of calf } \\
\hline Heifer & 0 & 0 & 0 & 0 & 0 & 0 & 0 & 0 & 0 \\
\hline Steer & 3.5 & 3.5 & 3.4 & 14 & 14 & 14 & 105 & 105 & 105 \\
\hline \multicolumn{10}{|c|}{ Age of dam, yr } \\
\hline 2 & 0 & 0 & 0 & 0 & 0 & 0 & 0 & 0 & 0 \\
\hline 3 & 2.0 & 1.9 & 1.9 & 25 & 25 & 24 & 24 & 24 & 24 \\
\hline 4 & 4.1 & 4.1 & 4.1 & 39 & 40 & 39 & 35 & 35 & 35 \\
\hline$>4$ & 4.4 & 4.4 & 4.5 & 44 & 44 & 44 & 37 & 37 & 37 \\
\hline
\end{tabular}


Table 9. Apparent standard errors $(\mathrm{kg})$ of breed of sire contrasts for birth weight, weaning weight, and yearling weight for models ignoring grandam effects $\left(R\right.$ and $\left.R_{m}\right)$, including random sire or maternal grandsire effects (RS and $\mathrm{RS}_{\mathrm{m}}$ ), and also including random dam or daughter within maternal grandsire effects (RSD and $\mathrm{RSD}_{\mathrm{m}}$ )

\begin{tabular}{|c|c|c|c|c|c|c|c|c|c|c|c|c|}
\hline \multirow[b]{2}{*}{ Breed of sire } & \multicolumn{3}{|c|}{ Birth weight } & \multicolumn{3}{|c|}{ Weaning weight } & \multicolumn{3}{|c|}{ Yearling weight } & \multicolumn{3}{|c|}{ Maternal weaning weight } \\
\hline & $\mathrm{R}$ & RS & RSD & $\mathrm{R}$ & RS & RSD & $\mathrm{R}$ & RS & RSD & $R_{m}$ & $\mathrm{RS}_{\mathrm{m}}$ & $\mathrm{RSD}_{\mathrm{m}}$ \\
\hline P. Hereford & .25 & .40 & .40 & 1.7 & 2.3 & 2.1 & 2.8 & 4.1 & 4.0 & 1.6 & 3.2 & 3.2 \\
\hline Hereford & .29 & .40 & .40 & 1.8 & 2.4 & 2.2 & 2.9 & 4.3 & 4.2 & 1.5 & 3.1 & 3.1 \\
\hline Angus & 0 & 0 & 0 & 0 & 0 & 0 & 0 & 0 & 0 & 0 & 0 & 0 \\
\hline Shorthorn & .36 & .51 & .47 & 2.5 & 3.0 & 2.7 & 3.9 & 5.1 & 5.0 & 1.8 & 3.2 & 3.3 \\
\hline Brahman & .29 & .40 & .40 & 1.9 & 2.4 & 2.3 & 3.2 & 4.5 & 4.4 & 2.1 & 3.9 & 3.8 \\
\hline Simmental & .36 & .51 & .47 & 2.3 & 2.9 & 2.7 & 3.6 & 5.1 & 5.0 & 1.5 & 3.1 & 3.2 \\
\hline Limousin & .36 & .51 & .51 & 2.3 & 3.0 & 2.8 & 3.6 & 5.3 & 5.2 & 1.6 & 3.3 & 3.3 \\
\hline Charolais & .29 & .40 & .40 & 2.0 & 2.4 & 2.2 & 3.0 & 4.1 & 4.0 & 1.4 & 2.6 & 2.7 \\
\hline Maine-Anjou & .44 & .62 & .58 & 2.9 & 3.5 & 3.3 & 4.5 & 6.2 & 6.0 & 1.9 & 3.6 & 3.8 \\
\hline Gelbvieh & .33 & .47 & .47 & 2.2 & 2.8 & 2.6 & 3.4 & 4.9 & 4.8 & 1.5 & 3.0 & 3.0 \\
\hline Pinzgauer & .33 & .51 & .51 & 2.0 & 2.8 & 2.6 & 3.3 & 5.3 & 5.1 & 1.7 & 3.4 & 3.3 \\
\hline Tarentaise & .40 & .69 & .69 & 2.5 & 3.8 & 3.6 & 4.0 & 7.2 & 7.0 & 1.9 & 4.7 & 4.4 \\
\hline Salers & .36 & .51 & .47 & 2.5 & 2.9 & 2.7 & 3.8 & 5.0 & 4.9 & 1.6 & 3.0 & 3.1 \\
\hline
\end{tabular}

Standard errors were not as affected by the change of model for these contrasts. Apparent standard errors of AOD and BOD contrasts increased as sources of variation were removed. Neither sire nor dam variance was expected to contribute significantly to these contrasts because AOD and SEX are cross-classified with sires and dams. As a result, apparent standard errors were primarily affected by residual variance, which increased when sires and dams were removed from the models.

\section{Implications}

Models that ignored random effects of sires or of sires and dams resulted in standard errors of sire

Table 10. Ranges for birth weight, weaning weight, and yearling weight in apparent standard errors $(\mathrm{kg})$ of fixed effect contrasts for models ignoring random effects (R), including random sire effects (RS), and including random dam effects (RSD)

\begin{tabular}{|c|c|c|c|}
\hline Item & $\mathrm{R}$ & RS & RSD \\
\hline \multicolumn{4}{|l|}{$\operatorname{Sex}^{\mathrm{a}}$} \\
\hline Birth weight & .14 & .14 & .14 \\
\hline Weaning weight & .7 & .7 & .7 \\
\hline Yearling weight & 1.2 & 1.1 & 1.1 \\
\hline \multicolumn{4}{|l|}{ Age of damb } \\
\hline Birth weight & $.23-.41$ & $.23-.36$ & $.23-.36$ \\
\hline Weaning weight & $1.3-2.2$ & $1.3-2.1$ & $1.2-2.0$ \\
\hline Yearling weight & $2.0-3.5$ & $2.0-3.3$ & $1.9-3.3$ \\
\hline \multicolumn{4}{|l|}{ Breed of damc } \\
\hline Birth weight & .18-.36 & $.36-.36$ & $.18-.36$ \\
\hline Weaning weight & $.9-2.0$ & $.9-2.0$ & $1.0-2.0$ \\
\hline Yearling weight & $1.4-3.2$ & $1.4-3.1$ & $1.5-3.2$ \\
\hline
\end{tabular}

${ }^{a}$ Contrast vs heifer

${ }^{\mathrm{b}}$ Contrast vs age of $2 \mathrm{yr}$.

cContrast vs Angus. breed differences that were underestimated relative to standard errors with the complete model. Standard errors of fixed effects cross-classified with random effects were generally unchanged. Estimates of breed of sire solutions and contrasts of fixed effects changed only slightly and with no apparent pattern when random effects of sires and dams were ignored. Generally, rankings of effects did not change significantly. Underestimation of standard errors of breed of sire comparisons will result in underestimation of prediction error variances associated with acrossbreed EPD. As a result, breed of sire comparisons and standard errors resulting from a model including random effects of sires and dams (or maternal grandsires and daughters of maternal grandsires) should be used to calculate adjustment factors for across-breed EPD and prediction error variances.

\section{Literature Cited}

Barkhouse, K. L., L. D. Van Vleck, and L. V. Cundiff. 1994. Breed comparisons for growth and maternal traits adjusted to a 1992 base. Proc. Beef Improvement Federation Annu. Mtg. West Des Moines, IA. pp 197-209.

Boldman, K. G., L. A. Kriese, L. D. Van Vleck, and S. D. Kachman. 1993. A manual for use of MTDFREML: A set of programs to obtain estimates of variances and covariances. $p$ 120. USDA Meat Animal Research Center, Clay Center, NE.

Cundiff, L. V. 1993. Breed comparisons adjusted to a 1991 basis using current EPD. Proc. Beef Improvement Federation Annu. Mtg., Asheville, NC. pp 114-123.

Gill, J. L. 1991. Biases in balanced experiments with uncontrolled random factors. J. Anim. Breed. Genet. 108:69-85.

Gregory, K. E., L. V. Cundiff, R. M. Koch, D. B. Laster, and G. M. Smith. 1978. Heterosis and breed maternal and transmitted effects in beef cattle. I. Preweaning traits. J. Anim. Sci. 47: 1031-1041.

Gregory, K. E., D. B. Laster, L. V. Cundiff, G. M. Smith, and R. M. Koch. 1979. Characterization of biological types of cattle-Cycle 
III: II. Growth rate and puberty in females. J. Anim. Sci. 49: 461-471.

Komender, P., and I. Hoeschele. 1989. Use of mixed-model methodology to improve estimation of crossbreeding parameters. Livest. Prod. Sci. 21:101-113.

Long, C. R. 1980. Crossbreeding for beef production: Experimental results. J. Anim. Sci. 51:1197-1223.

Notter, D. R., and L. V. Cundiff. 1991. Across-breed expected progeny differences: Use of within-breed expected progeny differences to adjust breed evaluations for sire sampling and genetic trend. J. Anim. Sci. 69:4763-4776.

Notter, D. R., L. V. Cundiff, G. M. Smith, D. B. Laster, and K. E. Gregory. 1978. Characterization of biological types of cattle. VII. Milk production in young cows and transmitted and mater- nal effects on preweaning growth of progeny. J. Anim. Sci. 46: 908-921.

Núñez-Dominguez, R., L. D. Van Vleck, and L. V. Cundiff. 1993. Breed comparisons for growth traits adjusted for within-breed genetic trend using expected progeny differences. J . Anim. Sci. 71:1419-1428.

Smith, G. M., D. B. Laster, and K. E. Gregory. 1976. Characterization of biological types of cattle. I. Dystocia and preweaning growth. J. Anim. Sci. 43:27-36.

Souza, J . C. 1993. Effects of weather and breed on the performance of crossbred beef cattle. M.S. Thesis. Univ. of Nebraska, Lincoln. p 108.

Van Vleck, L. D., and L. V. Cundiff. 1994. Prediction error variances for interbreed genetic evaluations. J . Anim. Sci. 72:1971-1977. 